DOI 10. 18307/2017. 0513

(c) 2017 by Journal of Lake Sciences

\title{
淮北临涣矿采煤沉陷区不同水体水化学特征及其影响因素
}

\author{
孔令健, 姜春露林, 郑刘根, 程 桦, 任梦溪, 闵飞虎, 方刘兵 \\ (安徽大学资源与环境工程学院矿山环境修复与湿地生态安全协同创新中心, 合肥 230601)
}

\begin{abstract}
摘 要: 为研究淮北临涣矿采煤沉陷区不同水体的补给水源及溶质来源,在现场调查的基础上,系统采集丰水期、平水 期、枯水期沉陷区积水、地表河水和浅层地下水样进行测试分析,采用 Piper 三线图、Gibbs 图和因子分析方法,对不同水 体水化学特征及其影响因素进行讨论. 结果表明: 地表水水体总溶解性固体 (TDS) 质量浓度表现为枯水期 >丰水期 $>$ 平水 期,浅层地下水表现为枯水期 $>$ 平水期 $>$ 丰水期, 地表水 TDS 质量浓度明显高于浅层地下水. 地表水中主要阴阳离子为 $\mathrm{Na}^{+} 、 \mathrm{Cl}^{-}$和 $\mathrm{SO}_{4}^{2-}$, 水化学类型主要为 $\mathrm{SO}_{4}^{2-}-\mathrm{Cl}^{-}-\mathrm{Na}^{+}$型; 浅层地下水离子以 $\mathrm{HCO}_{3}^{-} 、 \mathrm{Ca}^{2+}$ 和 $\mathrm{Mg}^{2+}$ 为主, 表现为 $\mathrm{HCO}_{3}^{-}-$ $\mathrm{Ca}^{2+}-\mathrm{Mg}^{2+}$ 型. 结合 Gibbs 图和因子分析可知, 地表水受蒸发作用、地表径流以及采煤活动等因素影响, 浅层地下水在一定 程度上体现出大气降水和地表水补给的特点,受岩石风化作用影响较为明显.
\end{abstract}

关键词: 采煤沉陷区;地表水;浅层地下水;水化学特征;Gibbs 图; 因子分析

\section{Characters of hydrochemistry and their influenced factors of different waters in the Linhuan coal mining subsidence area of Huaibei City}

KONG Lingiian, JIANG Chunlu** , ZHENG Liugen, CHENG Hua, REN Mengxi, MIN Feihu \& FANG Liubing (Collaborative Innovation Center for Mines Environmental Remediation and Wetland Ecological Security, School of Resource and Environment Engineering, Anhui University, Hefei 230601, P.R.China)

Abstract: In order to research the interaction of water sources and dissolved solids in surface water and groundwater in the Linhuan coal mining subsidence area, 81 water samples were collected from surface water and groundwater during the periods of wet period, median water period, and dry period. The concentrations, compositions and types of major ions were analyzed. The influence factors were discussed by Piper graph, Gibbs graph and the method of factor analysis. The results indicate that: Total dissolved solids (TDS) are in the order of dry season > wet season > median water period in surface water, and in the order of dry period $>$ median water period > wet period in groundwater. The TDS of surface water are obviously higher than those of groundwater. $\mathrm{Na}^{+}, \mathrm{Cl}^{-}$and $\mathrm{SO}_{4}^{2-}$ are major ions in surface water, and mainly belong to the water chemistry type of $\mathrm{SO}_{4}^{2-}-\mathrm{Cl}^{-}-\mathrm{Na}^{+} . \mathrm{HCO}_{3}^{-}, \mathrm{Ca}^{2+}$ and $\mathrm{Mg}^{2+}$ are major ions in groundwater, and belong to the water chemistry type of $\mathrm{HCO}_{3}^{-}-\mathrm{Ca}^{2+}-\mathrm{Mg}^{2+}$. The Gibbs graph and factor analysis show that intense evaporation process, surface runoff and mining activities occurred in the surface water. To a certain extent, shallow groundwater reflects the characteristics of atmospheric precipitation and recharges of surface water, which is mainly influenced by rock weathering degrees.

Keywords: Coal mining subsidence area; surface water; shallow groundwater; characters of hydrochemistry; Gibbs graph; factor analysis

长期以来,煤炭资源大规模高强度的开采形成大面积的采煤沉陷区. 在我国东部,由于降水较为丰富, 加之高潜水位的水文地质条件,采煤沉陷区往往积水,形成人工沉陷水域. 据不完全统计,截止 2015 年,仅 两淮矿区采煤沉陷面积达 $508 \mathrm{~km}^{2[1]}$. 近几年,为配合国家生态文明建设和安徽省生态强省战略的实施,有

* 安徽省国土资源科技项目 (2013-K-07)、安徽省自然科学基金项目 (1408085QD70) 和安徽省教育厅重点项目 (KJ2014A018) 联合资助. 2016-08-23 收稿;2016-11-16 收修改稿. 孔令健 (1990 ), 男, 硕士; E-mail : timingkong@163.com.

** 通信作者; E-mail: cumtclj@ cumt.edu.cn. 
研究者提出将采煤沉陷区打造为 “平原水库” 的设想 ${ }^{[2]}$. 这样不仅可以提高地处淮河中段的两淮地区的防洪 能力, 还能解决周边地区因降水时间分配不均造成的干旱缺水问题, 同时还能建设人工湿地公园, 发挥其生 态功能.

要建设 “平原水库”, 水资源评价是首要问题, 而水化学特征是水资源评价的重要内容之一. 水体的水化 学组成特征在很大程度上表征水体环境质量状况、区域环境化学特征、水体元素分布及迁移转化规律 ${ }^{[3]}$. 水 体主要离子是其常量元素的主要存在形式,被广泛应用于识别水体化学组成的基本过程,如流域岩石风化、 水体蒸发/结晶作用、大气沉降及人为输人的相互联系等 ${ }^{[4]}$. 国内外许多学者对长江、黄河、大型湖泊 ${ }^{[5-8]}$ 等 地表主要水体的常量离子组成、来源及影响因素等开展了大量研究. 对于地下水水化学特征的研究,主要集 中在地下不同含水层水体 ${ }^{[9-12]}$, 这些研究为地下含水层水源识别提供了科学依据. 近年来, 已有相关学者开 始关注沉陷区积水水环境问题. 如孙鹏飞等 ${ }^{[13]}$ 对两淮矿区沉陷积水水化学特征及其影响因素进行探讨, 王 婷婷等 ${ }^{[14]}$ 、易齐涛等 ${ }^{[15]}$ 对淮南采煤沉陷区沉陷积水水体富营养化等开展了研究, 郑刘根等 ${ }^{\left[{ }^{[16]}\right.}$ 研究了非稳 沉采煤沉陷区沉积物一水体界面氮磷分布及迁移转化特征. 虽然前人已对地下含水层水和采煤沉陷区地表 水开展了较多研究, 但多数都是从地下工程水害防治和地表水环境特征两个角度, 把地表水和地下水分开 考虑, 二者的综合考虑较少. 对于两淮采煤沉陷区, 由于地下水埋藏浅、水位高, 地表水和浅层地下水可能存 在较大的水力联系, 尤其需要把二者综合起来研究. 为此, 本研究以淮北临涣矿采煤沉陷区为研究区域, 采 集沉陷积水、地表河 (渠) 水和浅层地下水进行测试分析, 研究不同水体常规水化学特征,并探讨其主要溶质 来源及影响因素, 以期为采煤沉陷区水资源评价和“平原水库”建设提供一定的科学依据.

\section{1 材料与方法}

\section{1 研究区概况}

临涣矿采煤沉陷区位于淮北市南部,其中浍河是流经该区的最大河流,自西北向东南流人洪泽湖,夏季 7-9 月份雨水多,水位上涨, 冬季 11月份到次年 3 月份降雨量减小, 水位降低. 沉陷区地表积水主要集中在 临涣工业园以北, 浍河以南, 韩村镇以西 (图 1). 沉陷区积水面积随沉陷年份逐渐增加. 目前, 沉陷区积水主 体部分近似为矩形, 东西长约 $1.5 \mathrm{~km}$, 南北宽约 $1.0 \mathrm{~km}$, 面积约 $1.5 \mathrm{~km}^{2}$, 积水区域最深达 $9.6 \mathrm{~m}$. 沉陷区东面 为粉煤灰场和矸石山, 沉陷区西南方向为临涣工业园和小型研石山堆积, 北部有香顺沟与浍河相连. 该区属 黄淮海冲积平原, 区内地势平坦, 标高为 $26.5 \sim 28.5 \mathrm{~m}$.

研究区属暖温带半湿润季风气候区, 年平均气温 $15.2^{\circ} \mathrm{C}$, 年平均降水量为 $842.7 \mathrm{~mm}$, 年平均蒸发量为 $1045.2 \mathrm{~mm}$. 夏季以东南风为主, 雨水充足, 历年平均降水量为 $473.5 \mathrm{~mm}$, 超过全年降水量的一半以上; 冬季 以西北风为主,干燥寒冷,历年平均降水量为 $50.7 \mathrm{~mm}^{[17]}$.

煤系地层上部普遍沉积了巨厚新生界松散层, 从上至下共分为 4 个含水层和 3 个隔水层. 本次研究采 集浅层地下水位于第 1 含水层, 该含水层一般自地表垂深 $3.0 \sim 5.0 \mathrm{~m}$ 起, 底界深度为 $27.9 \sim 42.8 \mathrm{~m}$, 主要由细 砂夹薄层砂质黏土组成, 有砂层 3 7 层, 总厚度一般在 $20.0 \mathrm{~m}$ 左右, 分布稳定. 第 4 含水层直接覆盖在煤层 之上,第 3 隔水层厚度分布稳定, 有效地阻隔了 $1 、 2 、 3$ 含水层与下伏各含水层的水力联系 ${ }^{[17]}$.

\section{2 样品采集与测试}

本研究结合水文条件和季节变化, 分别于 2015 年 4 月 (平水期)、 7 月 (丰水期), 2016 年 1 月 (枯水期), 在淮北市临涣矿采煤沉陷区各布置了 27 个采样点 (包括 10 个地表水和 17 个地下水) (图 1). 地表水采集 浍河河水 (采样点 $\mathrm{S} 1 \sim \mathrm{S} 4$ ) 、香顺沟水 (采样点 $\mathrm{S} 5 \sim \mathrm{S} 7$ ) 和沉陷区积水 (采样点 $\mathrm{S} 8 \sim \mathrm{S} 10$ ) ; 地下水采集第一含 水层水 (采样点 D1 D17), 取样点来自居民长期使用的压水井, 埋深为 $10 \sim 20 \mathrm{~m}$. 地下水采样点选取地表水 附近以及沉陷区其他区域, 依据地下水系统特征和交通条件确定, 并结合现场情况, 以期反映研究区不同位 置地下水特点. 所有样品取样均采用 $500 \mathrm{ml}$ 高密度聚乙烯塑料瓶, 预先用原水反复冲洗样瓶, 并于 $0 \sim 4^{\circ} \mathrm{C}$ 保 存水样.

水样通过 $0.45 \mu \mathrm{m}$ 微孔滤膜进行过滤. 阴离子 $\left(\mathrm{SO}_{4}^{2-} 、 \mathrm{Cl}^{-} 、 \mathrm{~F}^{-}\right)$采用离子色谱仪 ( ICS-1500, 戴安, 美国) 测 定; 阳离子 $\left(\mathrm{K}^{+} 、 \mathrm{Ca}^{2+} 、 \mathrm{Na}^{+} 、 \mathrm{Mg}^{2+}\right)$ 采用微波消解仪 ( speed wave ${ }^{\mathrm{TM}} \mathrm{MES}-3^{+}$, Berghof 公司, 德国) 消解后, 通过电 感耦合等离子体发射光谱仪 (IRIS Intrepid II XSP, Thermo Fisher Scientific 公司, 美国) 进行测定; $\mathrm{HCO}_{3}^{-}$测定 
采用双指示剂滴定法; 水体总溶解固体 (TDS) 质量浓度采用阴、阳离子质量浓度之和减去 $1 / 2 \mathrm{HCO}_{3}^{-}$质量浓 度方法计算. 实验室所用试剂均为优级纯, 用水为超纯水, 实验器血均用 $1: 10 \mathrm{HNO}_{3}$ 溶液浸泡 $24 \mathrm{~h}$ 后, 再用 去离子水清洗、烘干. 为保证测试准确度, 对其主要阴、阳离子守恒进行计算, 其物质的量浓度比值在 $1.00 \pm$ 0.25 时, 认为离子守恒, 否则重新测定 ${ }^{[18]}$.

\section{3 数据处理方法}

统计地表水和地下水不同季节各离子指标的最小值、最大值和平均值, 地下水和地表水 Piper 三线图、 Gibbs 图分别采用 AquaChem 3.7 和 Origin 8.5 绘制, 离子来源解析采用 SPSS 19.0 中“因子分析” 模块进行.

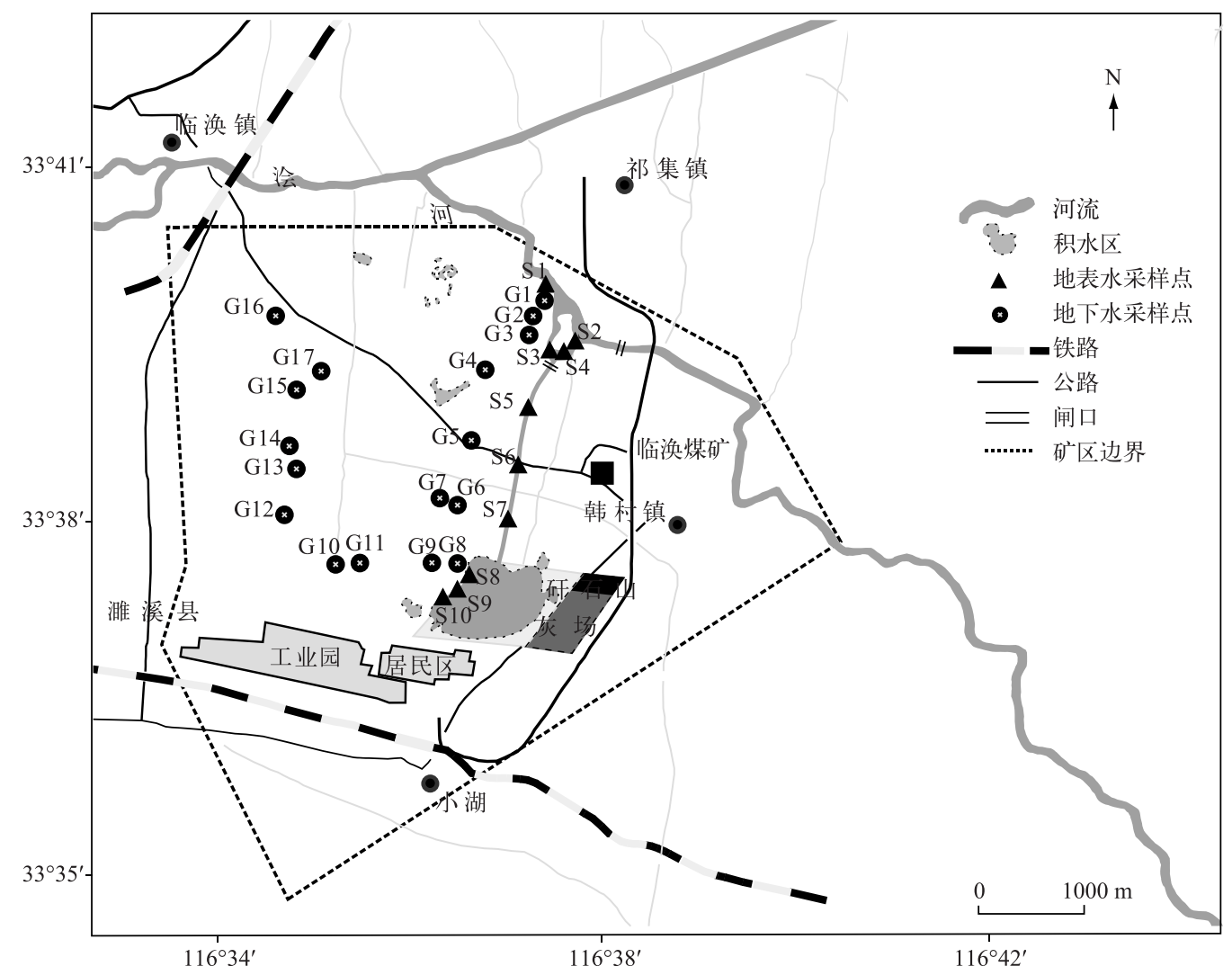

图 1 临涣矿采煤沉陷区地表水和地下水采样点分布

Fig. 1 Distribution of surface water and groundwater sampling sites in the Linhuan coal mining subsidence area

\section{2 结果与讨论}

经实地考察和研究发现, 沉陷区积水和地表河 (渠) 水为连通水域, 水化学组成及离子质量浓度无明显 差异,因此放在一起合称为地表水, 与浅层地下水对比分析.

\section{1 水化学特征分析}

2.1 .1 主要离子组成及质量浓度临涣矿采煤沉陷区地表水主要离子的质量浓度随时间变化明显(表 1 ). 除 $\mathrm{Mg}^{2+}$ 外, 丰水期、平水期、枯水期主要离子质量浓度均值呈依次增大趋势; 其中阳离子平均质量浓度顺序为: $\mathrm{Na}^{+}>\mathrm{Ca}^{2+}>\mathrm{Mg}^{2+}>\mathrm{K}^{+}$; 阴离子为 : $\mathrm{SO}_{4}^{2-}>\mathrm{HCO}_{3}^{-}>\mathrm{Cl}^{-}$. 3 个时期 TDS 质量浓度均值变化为: 枯水期 $(1562.9 \mathrm{mg} / \mathrm{L})>$ 平水期 $(1301.5 \mathrm{mg} / \mathrm{L})>$ 丰水期 $(1170.6 \mathrm{mg} / \mathrm{L})$.

不同时期地下水的平均离子质量浓度比较接近(表 2), 较地表水变化不明显, 阳离子以 $\mathrm{Ca}^{2+} 、 \mathrm{Na}^{+} 、 \mathrm{Mg}^{2+}$ 为主, 平均质量浓度顺序为: $\mathrm{Ca}^{2+}>\mathrm{Na}^{+}>\mathrm{Mg}^{2+}>\mathrm{K}^{+}$; 阴离子以 $\mathrm{HCO}_{3}^{-}$为主, 平均质量浓度顺序为: $\mathrm{HCO}_{3}^{-}>\mathrm{SO}_{4}^{2-}>$ 
$\mathrm{Cl}^{-}$. TDS 质量浓度均值变化为: 枯水期 $(440.0 \mathrm{mg} / \mathrm{L})>$ 平水期 $(412.4 \mathrm{mg} / \mathrm{L})>$ 丰水期 $(404.7 \mathrm{mg} / \mathrm{L})$.

表 1 采煤沉陷区不同时期地表水水化学统计特征 $(\mathrm{mg} / \mathrm{L})$

Tab.1 Hydrochemistry statistical characteristics in different periods of surface water in the coal mining subsidence area

\begin{tabular}{|c|c|c|c|c|c|c|c|c|c|c|}
\hline 时期 & & $\mathrm{K}^{+}$ & $\mathrm{Ca}^{2+}$ & $\mathrm{Na}^{+}$ & $\mathrm{Mg}^{2+}$ & $\mathrm{F}^{-}$ & $\mathrm{SO}_{4}^{2-}$ & $\mathrm{Cl}^{-}$ & $\mathrm{HCO}_{3}^{-}$ & TDS \\
\hline \multirow[t]{3}{*}{ 丰水期 } & 最小值 & 12.3 & 76.5 & 180.8 & 70.2 & 1.0 & 388.7 & 146.8 & 330.6 & 1041.6 \\
\hline & 最大值 & 15.0 & 90.4 & 239.9 & 79.5 & 1.6 & 525.8 & 166.6 & 361.4 & 1299.5 \\
\hline & 平均值 & 13.5 & 84.5 & 205.0 & 71.8 & 1.2 & 442.7 & 156.4 & 344.7 & 1170.6 \\
\hline \multirow[t]{3}{*}{ 平水期 } & 最小值 & 12.9 & 87.5 & 233.4 & 66.4 & 1.2 & 508.0 & 150.3 & 334.4 & 1226.9 \\
\hline & 最大值 & 15.5 & 96.6 & 266.7 & 75.9 & 1.8 & 560.8 & 172.6 & 372.4 & 1376.1 \\
\hline & 平均值 & 13.8 & 92.4 & 248.3 & 70.7 & 1.5 & 528.4 & 161.3 & 352.2 & 1301.5 \\
\hline \multirow[t]{3}{*}{ 枯水期 } & 最小值 & 13.5 & 93.6 & 277.6 & 70.3 & 1.8 & 597.3 & 172.8 & 362.2 & 1408.0 \\
\hline & 最大值 & 16.2 & 118.4 & 317.4 & 81.2 & 2.3 & 776.1 & 199.5 & 413.5 & 1717.8 \\
\hline & 平均值 & 14.5 & 104.6 & 292.5 & 75.1 & 1.9 & 682.8 & 183.0 & 395.0 & 1562.9 \\
\hline
\end{tabular}

临涣矿采煤沉陷区地表水阴、阳离子平均质量浓度均高于地下水, 其中地表水的 $\mathrm{K}^{+} 、 \mathrm{Na}^{+} 、 \mathrm{SO}_{4}^{2-} 、 \mathrm{Cl}^{-}$和 TDS 平均质量浓度明显高于地下水, $\mathrm{F}^{-} 、 \mathrm{HCO}_{3}^{-}$接近. 从地表水 TDS 质量浓度来看,该区地表水属于较高矿化 度水, 其矿化度远高于我国大型河湖, 如鄱阳湖 ${ }^{[7]}$ 、淮河河南段 ${ }^{[13]}$ 等, 但与周边河流,如东沙河、沱河、浴河等 相近 ${ }^{[19]}$, 表明区域气候条件产生强烈的“蒸发沉淀” 作用, 导致地表水体的 TDS 质量浓度升高. $\mathrm{SO}_{4}^{2-}$ 质量浓 度相对非采煤区高, 除受气候条件影响之外, 可能还来自于煤矿矿井排水 ${ }^{[20]}$ 以及煤研石的自然淋滤 过程 ${ }^{[21]}$.

表 2 采煤沉陷区不同时期地下水水化学统计特征 $(\mathrm{mg} / \mathrm{L})$

Tab.2 Hydrochemistry statistical characteristics in different periods of groundwater in the coal mining subsidence area

\begin{tabular}{ccccccccccc}
\hline 时期 & & $\mathrm{K}^{+}$ & $\mathrm{Ca}^{2+}$ & $\mathrm{Na}^{+}$ & $\mathrm{Mg}^{2+}$ & $\mathrm{F}^{-}$ & $\mathrm{SO}_{4}^{2-}$ & $\mathrm{Cl}^{-}$ & $\mathrm{HCO}_{3}^{-}$ & $\mathrm{TDS}$ \\
\hline \multirow{2}{*}{ 丰水期 } & 最小值 & 2.0 & 40.5 & 38.6 & 30.2 & 0.6 & 24.9 & 13.6 & 355.9 & 328.4 \\
& 最大值 & 2.8 & 57.5 & 53.9 & 48.4 & 1.8 & 48.0 & 43.2 & 450.9 & 481.0 \\
& 平均值 & 2.4 & 47.6 & 46.4 & 38.2 & 1.1 & 29.2 & 21.2 & 387.3 & 404.7 \\
\multirow{2}{*}{ 平水期 } & 最小值 & 3.0 & 41.6 & 43.6 & 32.5 & 0.6 & 27.2 & 13.5 & 367.2 & 345.6 \\
& 最大值 & 4.0 & 61.4 & 56.5 & 48.2 & 1.8 & 40.3 & 44.5 & 445.2 & 479.3 \\
& 平均值 & 3.5 & 51.8 & 47.8 & 38.7 & 1.1 & 33.7 & 22.1 & 392.9 & 412.4 \\
\multirow{2}{*}{ 枯水期 } & 最小值 & 3.6 & 40.5 & 44.3 & 32.6 & 1.6 & 28.5 & 15.0 & 363.9 & 348.0 \\
& 最大值 & 5.0 & 64.2 & 60.0 & 52.2 & 2.7 & 58.3 & 47.5 & 483.9 & 531.8 \\
& 平均值 & 4.4 & 50.9 & 49.6 & 40.2 & 2.0 & 37.0 & 23.0 & 405.3 & 440.0 \\
\hline
\end{tabular}

2.1.2 水化学类型特征 Piper 三线图为分析水化学组分的常用方法,利用水化学 Piper 三线图可以表明水体 主要离子组成变化以及不同水体化学组成特征, 并辨别其控制端元 ${ }^{[15]}$. 从 Piper 三线图 (图 2) 中可以看出, 在左下角阳离子三角图中, 地下水组分点靠近 $\mathrm{Ca}^{2+}-\mathrm{Mg}^{2+}$ 线上, 这两类离子主要来自碳酸盐岩的风化 ${ }^{[22]}$. 地 表水组分点偏向 $\left(\mathrm{K}^{+} 、 \mathrm{Na}^{+}\right)$端元, 说明流域中发生了岩盐的溶解 ${ }^{[22]}$, 但附近无大面积岩石出露, 推测主要原 因为沉陷区内农业用水中氮、磷污染所致 ${ }^{[23]}$. 另外地表水的蒸发作用或与黏土矿物进行离子交换都会增加 水中的 $\mathrm{K}^{+}$和 $\mathrm{Na}^{+}$离子浓度 ${ }^{[24]}$. 在右下角阴离子三角图中也有类似反映, 地下水组分点落在靠近 $\mathrm{HCO}_{3}^{-}$一端, 地表水组分点落在靠近 $\mathrm{SO}_{4}^{2-}-\mathrm{Cl}^{-}$线上, 而远离 $\mathrm{HCO}_{3}^{-}$一端, 出现 $\mathrm{SO}_{4}^{2-}$ 浓度过高的现象, 推测为采煤活动加速 硫铁矿被氧化导致其浓度增大 ${ }^{[20]}$. 丰水期、平水期、枯水期的地表水和地下水均表现出相同的离子组成,总 体上,地表水水化学类型表现为 $\mathrm{SO}_{4}^{2-}-\mathrm{Cl}^{-}-\mathrm{Na}^{+}$型, 浅层地下水水化学类型表现为 $\mathrm{HCO}_{3}^{-}-\mathrm{Ca}^{2+}-\mathrm{Mg}^{2+}$ 型.

水化学组成反映了该区域水文地质条件与生态环境的相关特征. 从水化学主要离子质量浓度和 Piper 


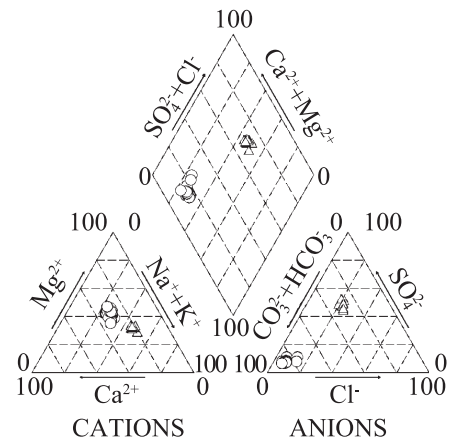

(a) 丰水期

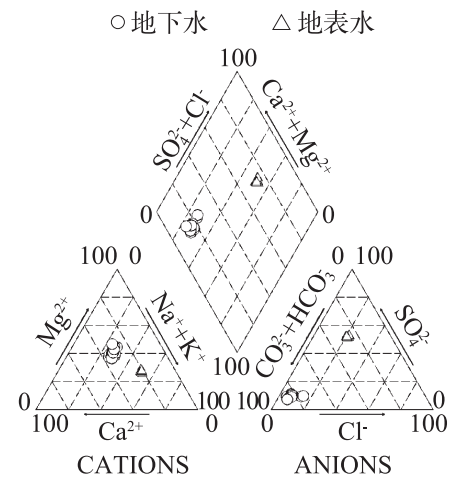

(b) 平水期

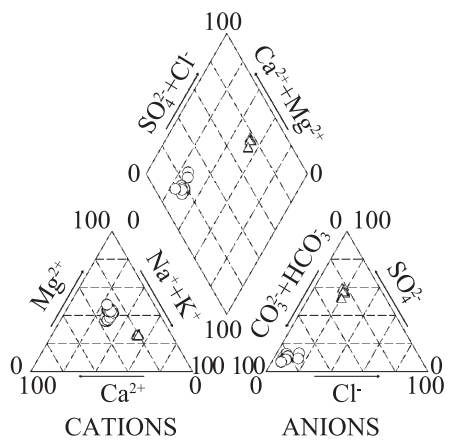

(c) 枯水期

图 2 不同时期地表水和地下水 Piper 三线图

Fig. 2 Piper diagrams in different periods of surface water and groundwater

三线图中地表水和地下水的离子组成来看, 地表水 (浍河水、香顺沟水及沉陷积水) 和地下水水化学特征差 异较大,地表水与周边地下水水力联系不明显. 造成地表水与浅层地下水水化学特征差异较大的原因分析 如下: (1) 地表沉陷并未改变原有表层土的组成, 因此沉陷积水区底部仍为黏土、砂质黏土组成 ${ }^{[17]}$; 浍河河 床也由黏土、淤泥质黏土组成, 二者均具有一定的隔水作用, 影响地表水和浅层地下水之间的联系. (2) 研究 区 9 个地下水位高程为 $22.6 \sim 25.8 \mathrm{~m}$, 地下水水力梯度平缓, 径流较弱; 另外, 沉陷区积水作为临涣水厂取水 源, 水位高程常年控制在 $24.2 \mathrm{~m}$, 浍河临涣段受临涣闸控制, 水位一般在 $24.6 \mathrm{~m}$ 左右, 地表水与地下水水位 差较小, 导致二者之间循环交替速度缓慢. (3) 经调查, 沉陷区积水总蓄水量为 $4.2 \times 10^{6} \mathrm{~m}^{3}$, 临涣水厂对沉陷 区积水年取水量为 $1.2 \times 10^{7} \sim 1.5 \times 10^{7} \mathrm{~m}^{3[1]}$, 沉陷区积水受浍河河水和大气降水补给, 更新速度快, 因此与地 下水水力联系程度变弱.

\section{2 水化学特征形成原因}

2.2.1 Gibbs 图 为了更直观地对影响水体离子特征的因素进行分析, 吉布斯设计了一种半对数坐标图 ${ }^{[25]}$. 其纵坐标以对数形式表示 TDS 质量浓度, 横坐标以算术值表示阳离子 $\rho\left(\mathrm{Na}^{+}\right) / \rho\left(\mathrm{Na}^{+}+\mathrm{Ca}^{2+}\right)$ 或阴离子 $\rho\left(\mathrm{Cl}^{-}\right) / \rho\left(\mathrm{Cl}^{-}+\mathrm{HCO}_{3}^{-}\right)$的比值 ${ }^{[26]}$. Gibbs 图能较清晰地反映出水体主要成分趋于 “大气降水类型”、“岩石风 化类型” 或 “蒸发-沉淀类型” ${ }^{[27]}$. 一般认为, TDS 质量浓度较低 $(10 \mathrm{mg} / \mathrm{L})$ 且具有较大的 $\rho\left(\mathrm{Na}^{+}\right) / \rho\left(\mathrm{Na}^{+}+\right.$ $\mathrm{Ca}^{2+}$ ) 或 $\rho\left(\mathrm{Cl}^{-}\right) / \rho\left(\mathrm{Cl}^{-}+\mathrm{HCO}_{3}^{-}\right.$) 比值 (接近 1) 的水体, 主要分布于 Gibbs 图的右下方, 反映出海洋起源的大气 降水影响; TDS 质量浓度较高 $(70 \sim 300 \mathrm{mg} / \mathrm{L})$ 且 $\rho\left(\mathrm{Na}^{+}\right) / \rho\left(\mathrm{Na}^{+}+\mathrm{Ca}^{2+}\right)$ 或 $\rho\left(\mathrm{Cl}^{-}\right) / \rho\left(\mathrm{Cl}^{-}+\mathrm{HCO}_{3}^{-}\right)$比值在 0.5 左右的水体, 主要分布于图的左侧中央, 反映出受岩石风化的影响; TDS 质量浓度较高且具有较大 $\rho\left(\mathrm{Na}^{+}\right) /$ $\rho\left(\mathrm{Na}^{+}+\mathrm{Ca}^{2+}\right)$ 或 $\rho\left(\mathrm{Cl}^{-}\right) / \rho\left(\mathrm{Cl}^{-}+\mathrm{HCO}_{3}^{-}\right)$比值 (接近于 1) 的水体, 其水化学类型与海水相似, 主要分布于图的 右上方, 反映出受干旱地区蒸发作用的影响. Gibbs 图解法除分析河水的离子起源外, 也可以分析地下水 ${ }^{[28]}$.

将临涣矿采煤沉陷区地表水和地下水的水化学数据投绘于 Gibbs 图中 (图 3), 发现临涣矿采煤沉陷区 不同时期地表水采样点的 TDS 质量浓度均较高, 且 $\rho\left(\mathrm{Na}^{+}\right) / \rho\left(\mathrm{Na}^{+}+\mathrm{Ca}^{2+}\right)$ 比值较大 $(0.68 \sim 0.75), \rho\left(\mathrm{Cl}^{-}\right) /$ $\rho\left(\mathrm{Cl}^{-}+\mathrm{HCO}_{3}^{-}\right)$比值较小 $(0.29 \sim 0.35)$, 体现了沉陷区地表水离子特征主要受蒸发作用影响, 且蒸发作用从丰水 期向枯水期呈现增强趋势. 不同时期地下水采样点变化趋势不明显, TDS 质量浓度中等, $\rho\left(\mathrm{Na}^{+}\right) / \rho\left(\mathrm{Na}^{+}+\mathrm{Ca}^{2+}\right)$ 比值为 $0.45 \sim 0.54, \rho\left(\mathrm{Cl}^{-}\right) / \rho\left(\mathrm{Cl}^{-}+\mathrm{HCO}_{3}^{-}\right)$比值为 $0.04 \sim 0.11$, 说明该沉陷区地下水受岩石风化和蒸发作用的 双重影响, 其中岩石风化为主要影响.

2.2.2 水化学因子分析 按丰水期、平水期、枯水期对离子质量浓度数据进行 Kaiser-Meyer-Olkin (KMO) 和 Bartlett 球形度检验, 3 个时期地表水和地下水的 KMO 统计均值分别为 0.85 和 0.79 ,均大于 0.50 , Bartlett 球 形度检验概率均为 0 , 表明在 $99 \%$ 的置信区间内显著相关. 因此, 数据适合作因子分析. 因子分析中抽取方 法选择主成分法, 采用 Varimax (最大正交旋转法) 对因子载荷进行旋转. 本研究的旋转载荷矩阵和贡献率见 

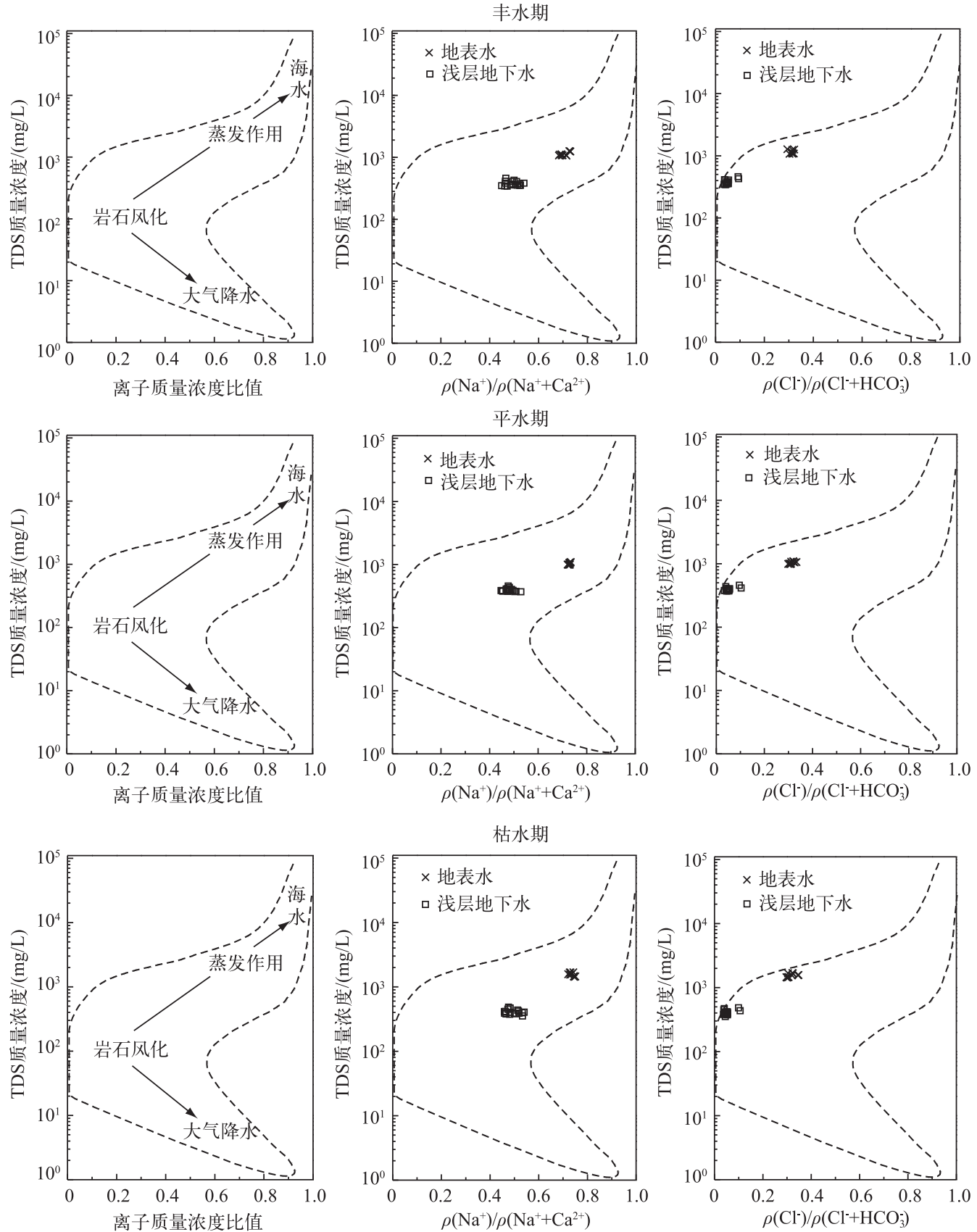

图 3 采煤沉陷区不同时期水化学吉布斯分布模式

Fig.3 Plots of the major ions within the Gibbs boomerang envelope for surface water and shallow groundwater in different periods in the coal mining subsidence area

表 $3 、 4$.

表 3 反映临涣矿采煤沉陷区地表水水化学影响因子,丰水期提取出 3 个因子:F1 贡献率为 $39.98 \%$, 影 响最大, 相关主要指标为 $\mathrm{K}^{+} 、 \mathrm{Ca}^{2+} 、 \mathrm{Na}^{+}$和 $\mathrm{SO}_{4}^{2-}$, 反映了地表水体的蒸发作用以及水体中易溶盐对水化学组分 
的重要影响; $\mathrm{F} 2$ 相关指标为 $\mathrm{Mg}^{2+}$ 和 $\mathrm{HCO}_{3}^{-}$, 其贡献率为 $25.08 \%$, 是由于碳酸盐岩等岩石风化的影响; $\mathrm{F} 3$ 与 $\mathrm{Cl}^{-}$呈正相关, 与 $\mathrm{F}^{-}$呈负相关, 表明含氟矿物经风化作用由大气降水淋溶, 呈现离子态或络合态, 随径流迁移 或补给地下水, 使 $\mathrm{F}^{-}$浓度呈下降趋势 ${ }^{[29]}$, 表现出丰水期地表水对地下水补给的特点. 平水期和枯水期相似, 均提取出 2 个因子, 分别与 $\mathrm{Ca}^{2+} 、 \mathrm{Na}^{+} 、 \mathrm{Mg}^{2+} 、 \mathrm{SO}_{4}^{2-}$ 和 $\mathrm{K}^{+} 、 \mathrm{HCO}_{3}^{-}$相关, 是由于碳酸盐岩等岩石风化以及水岩相 互作用产生的溶解作用 ${ }^{[24]}$. 其中 $\mathrm{SO}_{4}^{2-}$ 浓度较高可能是因为采煤活动加速硫铁矿被氧化而更多进人水体 ${ }^{[20]}$, 同时受到地表水流动过程中蒸发作用的影响 ${ }^{[19]}$, 后者与 Gibbs 图所示结果相吻合.

表 3 采煤沉陷区地表水水化学因子分析的旋转载荷矩阵和贡献率

Tab.3 Rotated component matrix and factor contribution to water solutes in terms of factor analysis of surface water in the coal mining subsidence area

\begin{tabular}{|c|c|c|c|c|c|c|c|}
\hline \multirow{2}{*}{ 离子变量 } & \multicolumn{3}{|c|}{ 丰水期 } & \multicolumn{2}{|c|}{ 平水期 } & \multicolumn{2}{|c|}{ 枯水期 } \\
\hline & $\mathrm{F} 1$ & $\mathrm{~F} 2$ & F3 & $\mathrm{F} 1$ & $\mathrm{~F} 2$ & $\mathrm{~F} 1$ & $\mathrm{~F} 2$ \\
\hline $\mathrm{K}^{+}$ & -0.79 & * & $*$ & * & 0.86 & $*$ & 0.92 \\
\hline $\mathrm{Ca}^{2+}$ & 0.88 & * & $*$ & 0.95 & $*$ & 0.93 & $*$ \\
\hline $\mathrm{Na}^{+}$ & 0.85 & $*$ & $*$ & 0.96 & $*$ & 0.93 & * \\
\hline $\mathrm{Mg}^{2+}$ & $*$ & 0.77 & $*$ & 0.70 & $*$ & 0.97 & $*$ \\
\hline $\mathrm{SO}_{4}^{2-}$ & 0.92 & $*$ & $*$ & 0.88 & $*$ & 0.92 & $*$ \\
\hline $\mathrm{Cl}^{-}$ & $*$ & $*$ & 0.89 & 0.98 & $*$ & $*$ & -0.82 \\
\hline $\mathrm{HCO}_{3}^{-}$ & $*$ & 0.95 & $*$ & 0.57 & 0.52 & $*$ & 0.80 \\
\hline $\mathrm{F}^{-}$ & $*$ & $*$ & -0.78 & $*$ & 0.84 & 0.65 & $*$ \\
\hline КMO & & 0.88 & & & 0.83 & \multicolumn{2}{|c|}{0.84} \\
\hline 贡献率/\% & 39.98 & 25.08 & 23.45 & 59.27 & 23.98 & 52.31 & 31.31 \\
\hline 累计贡献率/\% & 39.98 & 65.06 & 88.51 & 59.27 & 83.25 & 52.31 & 83.62 \\
\hline
\end{tabular}

F1、F2、F3 分别表示第 $1 、 2 、 3$ 因子; *表示变量的旋转公因子载荷值 $<0.5$, 下同.

表 4 采煤沉陷区地下水水化学因子分析的旋转载荷矩阵和贡献率

Tab.4 Rotated component matrix and factor contribution to water solutes in terms of factor analysis of groundwater in the coal mining subsidence area

\begin{tabular}{|c|c|c|c|c|c|c|c|c|c|}
\hline \multirow{2}{*}{ 离子变量 } & \multicolumn{3}{|c|}{ 丰水期 } & \multicolumn{3}{|c|}{ 平水期 } & \multicolumn{3}{|c|}{ 枯水期 } \\
\hline & F1 & $\mathrm{F} 2$ & F3 & $\mathrm{F} 1$ & $\mathrm{~F} 2$ & F3 & F1 & $\mathrm{F} 2$ & F3 \\
\hline $\mathrm{K}^{+}$ & $*$ & 0.82 & $*$ & $*$ & 0.86 & $*$ & 0.92 & $*$ & $*$ \\
\hline $\mathrm{Ca}^{2+}$ & 0.71 & $*$ & $*$ & 0.87 & $*$ & $*$ & 0.64 & 0.57 & $*$ \\
\hline $\mathrm{Na}^{+}$ & $*$ & 0.73 & $*$ & 0.81 & $*$ & $*$ & $*$ & 0.62 & $*$ \\
\hline $\mathrm{Mg}^{2+}$ & 0.94 & $*$ & $*$ & $*$ & * & 0.86 & $*$ & 0.60 & 0.65 \\
\hline $\mathrm{SO}_{4}^{2-}$ & 0.50 & $*$ & $*$ & $*$ & 0.87 & $*$ & 0.84 & $*$ & $*$ \\
\hline $\mathrm{Cl}^{-}$ & 0.54 & 0.73 & $*$ & $*$ & 0.71 & 0.54 & $*$ & $*$ & 0.86 \\
\hline $\mathrm{HCO}_{3}^{-}$ & 0.88 & $*$ & $*$ & 0.80 & $*$ & $*$ & $*$ & 0.98 & $*$ \\
\hline $\mathrm{F}^{-}$ & $*$ & $*$ & 0.95 & 0.59 & * & $*$ & $*$ & $*$ & 0.69 \\
\hline КMO & & 0.79 & & & 0.82 & & & 0.76 & \\
\hline 贡献率/\% & 34.01 & 26.35 & 19.01 & 32.37 & 28.94 & 20.91 & 27.80 & 25.67 & 22.89 \\
\hline 累计贡献率/\% & 34.01 & 60.36 & 79.37 & 32.37 & 61.31 & 82.22 & 27.80 & 53.47 & 76.36 \\
\hline
\end{tabular}

表 4 反映出临涣矿采煤沉陷区地下水水化学影响因子, 丰水期提取出 3 个因子, F1 贡献率为 $34.01 \%$, 相关指标为 $\mathrm{Ca}^{2+} 、 \mathrm{Mg}^{2+} 、 \mathrm{SO}_{4}^{2-} 、 \mathrm{Cl}^{-}$和 $\mathrm{HCO}_{3}^{-}$, 体现出碳酸盐岩等岩石风化影响的特点; $\mathrm{F} 2$ 相关指标为 $\mathrm{K}^{+} 、 \mathrm{Na}^{+}$ 和 $\mathrm{Cl}^{-}$, 反映出降水性控制以及人类活动对地下水化学形成的影响; $\mathrm{F} 3$ 贡献率为 $19.01 \%$, 该因子与 $\mathrm{F}^{-}$有很强 的相关性, 该地区 $\mathrm{F}^{-}$浓度相对较高, 主要来自含氟矿物 $\left(\mathrm{CaF}_{2}\right)$ 的溶解 ${ }^{[30]}$; 平水期 $\mathrm{F} 1$ 相关指标为 $\mathrm{Ca}^{2+} 、 \mathrm{Na}^{+}$、 
$\mathrm{HCO}_{3}^{-}$和 $\mathrm{F}^{-}$, 与枯水期 $\mathrm{F} 2$ 表现类似,受地表径流影响,均表现出水化学控制因素为碳酸盐岩风化的特点; 平 水期 $\mathrm{F} 2$ 相关指标为 $\mathrm{K}^{+} 、 \mathrm{SO}_{4}^{2-}$ 和 $\mathrm{Cl}^{-}$, 与农业活动及地表水补给有关; $\mathrm{F} 3$ 贡献率为 $20.91 \%$, 相关指标为 $\mathrm{Mg}^{2+}$ 和 $\mathrm{Cl}^{-}$, 反映受岩石风化作用和农业活动影响等多方面因素, 这与枯水期的 F3 来源相似; 枯水期 F1 控制指 标 $\mathrm{K}^{+} 、 \mathrm{Ca}^{2+}$ 和 $\mathrm{SO}_{4}^{2-}$ 表现出受易溶盐以及人类活动影响的特点.

综上所述,地表水和浅层地下水离子组成反映出该区域地质条件和气候的特点, 大气降水为主要补给 来源. 地表水离子组成来源主要为岩石风化和水岩相互作用, 表现出受蒸发作用及采煤活动影响的特征; 浅 层地下水离子组成主要来自于碳酸盐岩等岩石风化作用, 表现出受水体中易溶盐以及人类活动影响的特点.

\section{3 结论}

1) 临涣矿采煤沉陷区地表水体矿化度较高, 地表水丰水期、平水期、枯水期 TDS 平均质量浓度分别为 1170.6、1301.5 和 $1562.9 \mathrm{mg} / \mathrm{L}$, 是地下水的 3 倍左右,其主要原因是蒸发作用以及工、农业用水的影响.

2) Piper 三线图和 Gibbs 图共同表明,该区地表水水化学类型表现为 $\mathrm{SO}_{4}^{2-}-\mathrm{Cl}^{-}-\mathrm{Na}^{+}$型, 主要受蒸发作用影 响; 浅层地下水水化学类型表现为 $\mathrm{HCO}_{3}^{-}-\mathrm{Ca}^{2+}-\mathrm{Mg}^{2+}$ 型, 受岩石风化和蒸发作用的双重影响, 岩石风化为主要 作用.

3 ) 因子分析结果显示,地表水和浅层地下水相互补给较弱,二者主要离子来源为水岩相互作用产生的 溶蚀作用, 均体现出受大气降水补给的特点. 地表水离子组成受蒸发作用、地表径流以及采煤活动等因素影 响,浅层地下水主要受水体易溶盐的影响.

\section{4 参考文献}

[ 1 ] Cheng Hua, Xu Chong, Liu Guijian et al eds. Integration and demonstrations of the key technologies of eco-environment comprehensive control in Huainan and Huaibei coalmine subsidence areas. Hefei: Anhui University, 2015. [程桦, 徐羽, 刘桂建等. 两淮煤矿沉陷区生态环境综合治理关键技术集成与示范. 合肥: 安徽大学, 2015.]

[ 2 ] Zhang Lei, Qin Xiaoguang, Liu Jiaqi et al. Characters of hydrogen and oxygen stable isotope of different water bodies in Huainan coal mining area. Journal of Jilin University: Earth Science Edition, 2015, 45(5) : 1502-1514. [张否, 秦小光, 刘嘉麒等. 淮南采煤沉陷区积水来源的氢氧稳定同位素证据. 吉林大学学报: 地球科学版, 2015, 45(5): 1502-1514. ]

[ 3 ] Pu Tao, He Yuanqing, Zhu Guofeng et al. Geochemistry of surface and ground water in the Lijang Basin, Northwest Yunnan. Environment Science, 2012, 33(1) : 48-54. [蒲奉, 何元庆, 朱国锋等. 丽江盆地地表-地下水的水化学特征及 其控制因素. 环境科学, 2012, 33(1): 48-54.]

[ 4 ] Hou Zhaohua, Xu Hai, An Zhisheng. Major ion chemistry of waters in lake Qinghai catchment and the possible controls. Earth and Environment, 2009, 37(1): 11-19. [侯昭华, 徐海, 安芷生. 青海湖流域水化学主离子特征及控制因素 初探. 地球与环境, 2009, 37(1): 11-19.]

[ 5 ] Zhang Qianqian. Seasonal variation in river water chemistry of the middle reaches of the Yellow River and its controlling factors[ Dissertation]. Xi'an: Institute of Earth Environment, Chinese Academy of Sciences, 2015. [张茜茜. 黄河中游河 水化学季节性变化及其控制因素 [ 学位论文]. 西安: 中国科学院地球环境研究所, 2015.]

[ 6 ] Cao Deyun. Yangtze River source area water environment and hydrochemistry background characteristic [Dissertation]. Beijing: China University of Geosciences, 2013. [ 曹德云. 长江源区水环境及水化学背景特征 [学位论文]. 北京: 中国 地质大学, 2013.]

[ 7 ] Hu Chunhua, Zhou Wenbin, Xia Siqi. Characteristics of major ions and the influence factors in Poyang lake catchment. Environment Chemistry, 2011, 30(9) : 1620-1626. [胡春华, 周文斌, 夏思奇. 鄱阳湖流域水化学主离子特征及其来 源分析. 环境化学, 2011, 30(9): 1620-1626.]

[ 8 ] Ye Hongmeng, Yuan Xuyin, Ge Minxia et al. Water chemistry characteristics and controlling factors in the northern rivers in the Taihu basin. Ecology and Environmental Sciences, 2010, 19(1):23-27. [叶宏萌, 袁旭音, 葛敏霞等. 太湖北部 流域水化学特征及其控制因素. 生态环境学报, 2010, 19(1): 23-27.]

[ 9 ] Guo Gaoxuan, Hou Quanlin, Xu Liang et al. Delamination and zoning characteristics of quaternary groundwater in Chaobai alluvial-proluvial fan, Beijing, based on hydrochemical analysis. Acta Geoscientica Sinica, 2014, 35(2) : 204-210. [郭高 
轩, 侯泉林, 许亮等. 北京潮白河冲洪积扇地下水水化学的分层分带特征. 地球学报, 2014, 35(2): 204-210.]

[10] Carol E, Kruse E, Mas-Pla J. Hydrochemical and isotopical evidence of ground water salinization processes on the coastal plain of Samborombón Bay, Argentina. Journal of Hydrology, 2009, 365(3) : 335-345.

[11] Yang Q, Wang L, Ma H et al. Hydrochemical characterization and pollution sources identification of groundwater in Salawusu aquifer system of Ordos Basin, China. Environmental Pollution, 2016, 216: 340-349.

[12] Qian J, Wang L, Ma L et al. Multivariate statistical analysis of water chemistry in evaluating groundwater geochemical evolution and aquifer connectivity near a large coal mine, Anhui, China. Environmental Earth Sciences, 2016, 75(9):1-10.

[13] Sun Pengfei, Yi Qitao, Xu Guangquan. Characteristics of water chemistry and their influencing factors in subsidence waters in the Huainan and Huaibei mining areas, Anhui Province. Journal of China Coal Society, 2014, 39(7):1345-1353. [ 孙 鹏飞, 易齐涛, 许光泉. 两淮采煤沉陷积水区水体水化学特征及影响因素. 煤炭学报, 2014, 39(7): 1345-1353.]

[14] Wang Tingting, Yi Qitao, Hu Youbiao et al. Eutrophication and nutrient enrichment bioassays in the waters of the Huainan and Huaibei coal mining subsidence areas, Anhui Province. J Lake Sci, 2013, 25(6) : 916-926. DOI: 10.18307/2013. 0616. [王婷婷, 易齐涛, 胡友彪等. 两淮采煤沉陷区水域水体富营养化及氮、磷限制模拟实验. 湖泊科学, 2013, 25(6) : 916-926.]

[15] Yi Qitao, Sun Pengfei, Xie Kai et al. Impact of regional water chemistry on the phosphorus isothermal adsorption of the sediments in three subsidence waters of the Huainan mine areas. Environmental Science, 2013, 34(10) : 3894-3903. [易 齐涛, 孙鹏飞, 谢凯等. 区域水化学条件对淮南采煤沉陷区水域沉积物磷吸附特征的影响研究. 环境科学, 2013, 34(10) : 3894-3903.]

[16] Zheng Liugen, Liu Xiangxiang, Cheng Hua et al. Distribution and migration characteristics of nitrogen and phosphorus in sediment-water interface from unstable coal mining subsidence area. J Lake Sci, 2016, 28(1) : 86-93. DOI: 10.18307/ 2016.0110. [郑刘根, 刘响响, 程桦等. 非稳沉采煤沉陷区沉积物-水体界面的氮、磷分布及迁移转化特征. 湖泊科 学, 2016, 28(1): 86-93.]

[17] Cheng Hua, Zheng Liugen, Zhou Zhongze et al eds. The evolution of wetland ecosystem and sustainable utilization of water resources in Huaibei coalmine subsidence areas. Hefei: Anhui University, 2016. [程桦, 郑刘根, 周忠泽等. 淮北采煤 沉陷区湿地生态系统演变及水资源可持续利用研究. 合肥: 安徽大学, 2016.]

[18] Lin Yufei, Liu Sumei, Ji Lei et al. Chemical characteristic analysis on major ions of rainwater at Qianliyan Island in Spring and Summer. Marine Environmental Science, 2007, 26(2) : 116-120. [林雨霏, 刘素美, 纪雷等. 黄海春夏季降水中 常量离子化学特征分析. 海洋环境科学, 2007, 26(2): 116-120.]

[19] Chen Song, Gui Herong, Lin Manli et al. Chemical characteristics of river water in Huaibei coalfield, China and its significance. Earth and Environment, 2016, 44(4): 414-421. [陈松, 桂和荣, 林曼利等. 淮北煤田河流水化学特征及意 义. 地球与环境, 2016, 44(4): 414-421.]

[20] Zhang Ling. The effects on the kaste surface water quality of the coal mine exploiting[Dissertation]. Guiyang: Guizhou University, 2008. [张玲. 煤矿开采对喀斯特地区地表水环境质量的影响与评价 [学位论文]. 贵阳: 贵州大 学, 2008.]

[21] Gu Deming. Research of coal gangue storage impact on surface and shallow groundwater environment-A case of Panji mining area in Huainan[Dissertation]. Huainan: Anhui University of Science and Technology, 2015. [谷得明. 煤矸石堆存 对地表与浅层地下水环境的影响研究——以淮南潘集矿区为例 [学位论文]. 淮南: 安徽理工大学, 2015.]

[22] Zhang Yanan, Gan Yiqun, Li Xiaoqian et al. Water chemical characteristics and controlling factors of the Yangtze River in the wet season, 2013. Resources and Environment in the Yangtze Basin, 2016, (4): 645-654. [张亚男, 甘义群, 李小 倩等. 2013 年长江丰水期河水化学特征及控制因素. 长江流域资源与环境, 2016, (4) : 645-654.]

[23] Zhang Haichun, Hu Xiongxing, Han Zhonghao. The research of the water quality change and cause of Huangpu river system. Environmental Monitoring in China, 2013, 29(4): 55-59. [张海春, 胡雄星, 韩中豪. 黄浦江水系水质变化及原 因分析. 中国环境监测, 2013, 29(4): 55-59.]

[24] Lang Yunchao, Liu Congqiang, Zhao Zhiqi et al. Chemical composition of surface water and groundwater in Guiyang City: reactions of water and rocks and pollution characteristics in Karst hydrological system. Advances in Water Science, 2005,16 (6): 826-832. [郎齐超, 刘丛强, 赵志琦等. 贵阳市地表水地下水化学组成: 喀斯特水文系统水-岩反应及污染特 征. 水科学进展, 2005, 16(6): 826-832.]

[25] Tang Xiwen, Wu Jinkui, Xue Liyang et al. Major ion chemistry of surface water in the Xilin River Basin and the possible 
controls. Environmental Science, 2014, 35(1) : 131-142. [唐胥雯, 吴锦奎, 薛丽洋等. 锡林河流域地表水水化学主 离子特征及控制因素. 环境科学, 2014, 35(1): 131-142.]

[26] Gibbs RJ. Mechanisms controlling world water chemistry. Science, 1970, 170(3962) : 1088-1090.

[27] Kortatsi BK. Hydrochemical framework of groundwater in the Ankobra Basin, Ghana. Aquatic Geochemistry, 2007, 13(1) : 41-74.

[28] Jiao Yanjun, Wang Guangcai, Cui Linfeng et al. Characteristics of hydrochemistry and stable hydrogen, oxygen isotopes in surface water and groundwater in Jiyuan Basin. Environmental Chemistry, 2014, 33(6) : 963-968. [焦艳军, 王广才, 崔 霖峰等. 济源盆地地表水和地下水的水化学及氢、氧同位素特征. 环境化学, 2014, 33(6) : 963-968.]

[29] Xu Guangquan, Liu Jin, Zhu Qishun et al. Analysis of distribution characteristics and influencing factors for the fluorine in the shallow groundwater in Huaibei plain of Anhui. Journal of Water Resources and Water Engineering, 2009, 20(5) : 913. [许光泉, 刘进, 朱其顺等. 安徽淮北平原浅层地下水中氟的分布特征及影响因素分析. 水资源与水工程学 报, 2009, 20(5): 9-13.]

[30] Ding Dan, Xu Guangquan, He Xiaowen et al. Chemical characteristics and influential factors of fluorine ions in shallow groundwater of Huaibei Plain. Water Resources Protection, 2009, 25(2) : 64-68. [丁丹, 许光泉, 何晓文等. 淮北平原 浅层地下水氟的水化学特征及影响因素分析. 水资源保护, 2009, 25(2): 64-68.] 